University of Nebraska - Lincoln

DigitalCommons@University of Nebraska - Lincoln

Publications from USDA-ARS / UNL Faculty

U.S. Department of Agriculture: Agricultural

Research Service, Lincoln, Nebraska

2001

\title{
Latitudinal and Longitudinal Adaptation of Smooth Bromegrass Populations
}

\author{
M. D. Casler \\ University of Wisconsin-Madison, michael.casler@ars.usda.gov \\ Kenneth P. Vogel \\ University of Nebraska-Lincoln, kvogel1@unl.edu \\ J. A. Balasko \\ West Virginia University \\ J. D. Berdahl \\ USDA-ARS \\ D. A. Miller \\ University of Illinois \\ See next page for additional authors
}

Follow this and additional works at: https://digitalcommons.unl.edu/usdaarsfacpub

Casler, M. D.; Vogel, Kenneth P.; Balasko, J. A.; Berdahl, J. D.; Miller, D. A.; Hansen, J. L.; and Fritz, J. O., "Latitudinal and Longitudinal Adaptation of Smooth Bromegrass Populations" (2001). Publications from USDA-ARS / UNL Faculty. 1912.

https://digitalcommons.unl.edu/usdaarsfacpub/1912

This Article is brought to you for free and open access by the U.S. Department of Agriculture: Agricultural Research Service, Lincoln, Nebraska at DigitalCommons@University of Nebraska - Lincoln. It has been accepted for inclusion in Publications from USDA-ARS / UNL Faculty by an authorized administrator of DigitalCommons@University of Nebraska - Lincoln. 


\section{Authors}

M. D. Casler, Kenneth P. Vogel, J. A. Balasko, J. D. Berdahl, D. A. Miller, J. L. Hansen, and J. O. Fritz 


\title{
Latitudinal and Longitudinal Adaptation of Smooth Bromegrass Populations
}

\author{
M. D. Casler,* K. P. Vogel, J. A. Balasko, J. D. Berdahl, D. A. Miller, J. L. Hansen, and J. O. Fritz
}

\begin{abstract}
Breeding progress has been slow in smooth bromegrass (Bromus inermis Leyss) since its introduction to North America. Much of the variability among cultivars appears to have arisen by natural selection and adaptive responses. The objective of this study was to determine if smooth bromegrass cultivars differ in latitudinal or longitudinal adaptation, as measured by forage yield, and if that variability relates to their breeding or selection history. The target region was defined as the Great Plains to the East Coast of the USA, from 38 to $47^{\circ} \mathrm{N}$ latitude. Twenty-nine cultivars and experimental populations were evaluated for forage yield at up to seven locations ranging from central to eastern USA. Populations were classified according to pooled population main effect and population $\times$ location interaction effect $(G+G L$ deviations). Cluster analysis resulted in eight clusters that explained $90 \%$ of the variation among G + GL deviations. One cluster consisted of populations average in adaptation, four clusters consisted of populations that were largely unadapted across the entire region, and three clusters consisted of populations that were specifically adapted to the entire region or a large part thereof. Much of the grouping and adaptation characteristics could be explained by similar pedigrees, selection history, and selection location. However, the phenotypic similarity of some superior, but divergent-pedigree populations suggested that alleles for high and stable forage yield in smooth bromegrass probably exist in numerous germplasm sources. Despite a history of little to no gains in forage yield, these results suggest unrealized potential for future improvement of forage yield of smooth bromegrass across a broad geographic region.
\end{abstract}

$\mathrm{S}$ MOOTH BROMEGRASS is native to eastern Europe and western Asia. It was introduced into North America in 1884 and spread rapidly throughout the Great Plains region, largely because of its superior performance in plot trials. Between 1942 and 1950, several cultivars were released as direct increases of introduced ecotypes or as naturalized selections of these ecotypes. Large differences among seed lots in establishment capacity and forage production provided the basis for these initial "land race" cultivars. 'Lincoln' has always been the most widely grown of these land races, presumably because of its superior performance in regional trials and

M.D. Casler, Dep. of Agronomy, Univ. of Wisconsin-Madison, Madison, WI 53706-1597; K.P. Vogel, USDA/ARS, Dep. of Agronomy, Univ. of Nebraska, Lincoln, NE 68583; J.A. Balasko, Div. of Plant and Soil Sci., West Virginia Univ., Morgantown, WV 26506-6108; J.D. Berdahl, USDA/ARS, Northern Great Plains Res. Lab., Mandan, ND 58544; D.A. Miller, Dep. of Crop Sci., Univ. of Illinois, Urbana, IL 61801; J.L. Hansen, Dep. of Plant Breeding and Biometry, Cornell Univ., Ithaca, NY 14853-1902; J.O. Fritz, Dep. of Agronomy, Kansas State Univ., Manhattan, KS 66506-5501. Joint contribution of the Illinois, Kansas, Nebraska, New York, West Virginia, and Wisconsin Agric. Exp. Stn., USDA/ARS, and the NE-144 Regional Research Committee, "Forage Crop Genetics and Breeding to Improve Yield and Quality." Univ. of Nebraska Journal Series No. 13178. Received 30 Oct. 2000. *Corresponding author (mdcasler@facstaff.wisc.edu).

Published in Crop Sci. 41:1456-1460 (2001). its name recognition (Thomas et al., 1958; Vogel et al., 1996).

Progress has been slow in breeding improved cultivars of smooth bromegrass in North America. While the collective group of cultivars developed since the release of Lincoln in 1942 have an average annual forage yield about $0.5 \mathrm{Mg} \mathrm{ha}^{-1}$ greater than Lincoln, there were no measurable increases in total forage yield during the latter half of the 20th century (Casler et al., 2000). The greatest gains have been for increased in vitro dry matter digestibility (IVDMD), disease resistance, and regrowth forage yield (Casler et al., 2000). Slow overall breeding progress in smooth bromegrass can be partly attributed to relatively low resources and lack of comprehensive and sustained efforts. No cultivar contains more than three cycles of selection and recombination from essentially wild or natural germplasm, and most cultivars represent one cycle of selection or less (Alderson and Sharp, 1994; Hanson, 1972). Therefore, much of the variability present among smooth bromegrass cultivars and breeding populations arose from natural selection and adaptive responses.

Smooth bromegrass cultivars and breeding populations are sensitive to genotype $\times$ location $(\mathrm{GL})$ interaction. Cultivar rankings for forage yield have low to moderate correlations between locations, many with negative values (Casler et al., 2000). Differential management factors among locations such as harvest frequency and nitrogen fertilization rate, and environmental factors such as soil type could not account for any part of the rank correlation pattern among locations (Casler et al., 2000, unpublished data). However, the combination of latitude and longitude differential within location pairs accounted for $22 \%$ of the variation in the pattern of 21 rank correlations for forage yield among seven locations (Casler et al., 2000, unpublished data). Longitude was the most important factor, decreasing rank correlations by 0.02 for each additional degree of longitude differential within a location pair. Previous studies have shown latitude to be an important factor regulating GL interactions for forage yield of smooth bromegrass, but have largely ignored GL interactions related to longitude (Knowles and White, 1949; Thomas et al., 1958).

The objective of this study was to determine if smooth bromegrass cultivars differ in latitudinal or longitudinal adaptation, as measured by forage yield, and if that variability relates to their breeding and selection history. This study represents the second part of a two-part analysis of smooth bromegrass populations and cultivars. Part two was initiated following the retrospective analysis of the matrix of rank correlation coefficients for forage yield at seven locations, described in the previous paragraph. The contrast analyses used in the first part (Casler et al., 2000) focused on breeding progress and 
did not lend themselves to any deterministic analysis of GL interactions for these populations and cultivars.

\section{MATERIALS AND METHODS}

Twenty-nine smooth bromegrass populations or cultivars were included in the experiment and their pedigrees were reported by Casler et al. (2000). Selection of specific entries and the total number of entries was based strictly on availability of seed. Due to insufficient seed, some entries were not planted at all locations. All cultivars were represented by certified seed and all experimental populations were represented by Syn-2 or later seed from breeders' increases.

The experiment was planted at seven locations in a randomized complete block design at each location (Fig. 1). Latitude, longitude, and soil types for each location are provided by Casler et al. (2000). There were three replicates at each location, except at Hutchinson, KS, and Mead, NE, where there were four replicates each. Plots were planted in spring 1991 in Illinois, Kansas, Nebraska, and Wisconsin, or in spring 1992 at the other locations. Plot size was 0.9 by $3.0 \mathrm{~m}$ in Illinois, West Virginia, and Wisconsin; 1.5 by $4.0 \mathrm{~m}$ in New York; 1.5 by $4.6 \mathrm{~m}$ in Kansas and Nebraska; and 1.5 by $6.1 \mathrm{~m}$ in North Dakota.

Seeding-year management involved occasional clipping to control annual weeds and nitrogen fertilization to stimulate seedling growth. Nitrogen fertilization during harvest years ranged from 45 to $112 \mathrm{~kg} \mathrm{~N} \mathrm{ha}^{-1}$ distributed in one to three applications per year (Casler et al., 2000). Fertilization with $\mathrm{P}$ and $\mathrm{K}$ was done according to soil test results. The number of harvests per year ranged from one to three and was largely dependent on precipitation and temperature (Casler et al., 2000). Variation in management among locations was due to use of locally derived "best recommended management" for smooth bromegrass, which varied widely among locations because of their geographic and climatic differences. Use of different management practices among locations is a widely accepted procedure employed in measuring crop yield gains because of breeding (Fehr, 1984; Veronesi, 1991) and ensures that estimates of genetic gains are realistic and have a broad inference range. Limited rainfall at some sites routinely prevents utilization of higher rates of $\mathrm{N}$ fertilizer and forces less frequent harvests than other sites. Therefore, each location is defined by a combination of soil type, climate, and management.

Data were collected beginning the year after seeding for all locations, except Nebraska and Wisconsin, for which stands

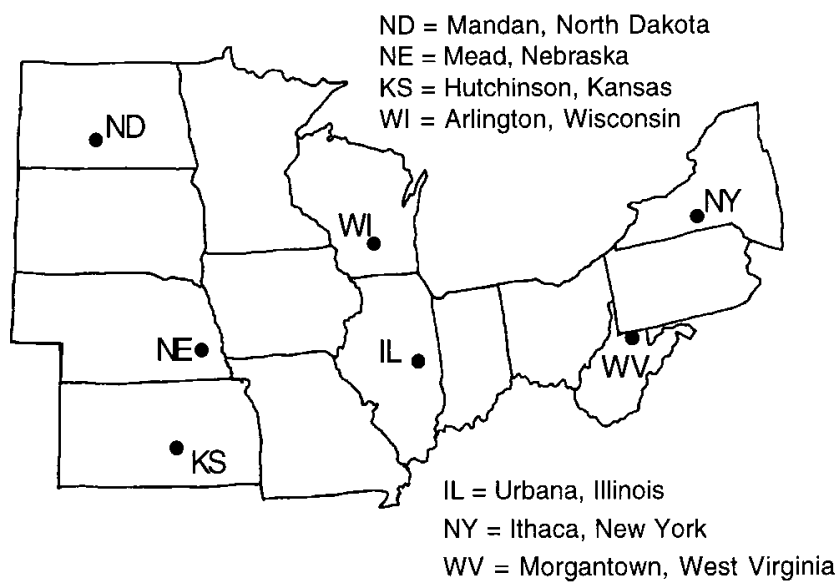

Fig. 1. Albers equal-area projection of a portion of the USA, showing seven locations used to evaluate 29 smooth bromegrass populations. were allowed to thicken for one additional year prior to data collection. Forage yield of the entire plot in Illinois, West Virginia, and Wisconsin, or a 0.9-m-wide swath in Kansas, Nebraska, New York, and North Dakota was measured following cutting with a flail chopper or sickle-bar mower. Cutting height was $9 \mathrm{~cm}$ at each location, except West Virginia $(7 \mathrm{~cm})$. A $300-$ to $500-\mathrm{g}$ fresh-weight sample was taken on each plot for dry matter determination. Average maturity stages of first harvest were as follows: Illinois-late jointing; Nebraska, New York, West Virginia, and Wisconsin-between head emergence and anthesis; North Dakota_-initial seed ripening; and Kansas - dough stage. Smooth bromegrass cultivar rankings are not affected by the timing of first harvest or the frequency of hay harvests (Fortman, 1953). Data were collected for $3 \mathrm{yr}$ at each location, except Kansas and New York (2 yr each).

Forage yields for each plot were averaged over years, because population $\times$ year interactions were generally not significant (Casler et al., 2000). Because of the lack of balance between populations and locations (Table 1), traditional population $\times$ location interactions could be estimated only for small subsets of populations and locations. Therefore, a method was devised which pooled the population and population $\times$ location interaction $(\mathrm{G}+\mathrm{GL})$ effects in a manner analogous to that of Lin and Binns (1988) for their unbalanced data set.

Each datum was converted into a deviation from the loca-

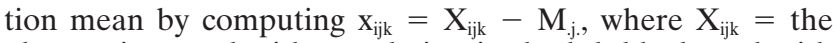
observation on the ith population in the kth block at the jth location and $\mathrm{M}_{\mathrm{j} .}=$ the mean of the jth location. A mixedmodels analysis was performed on the $\mathrm{x}_{\mathrm{ijk}}$ values by means of

Table 1. Mean forage yield for 29 smooth bromegrass populations evaluated at up to seven locations. Means are over three or four replicates and 2 or 3 yr.

\begin{tabular}{|c|c|c|c|c|c|c|c|}
\hline \multirow[b]{2}{*}{ Population } & \multicolumn{7}{|c|}{ Location $\dagger$} \\
\hline & IL & KS & $\mathbf{N E}$ & NY & ND & WV & WI \\
\hline & \multicolumn{7}{|c|}{ Mg ha $^{-1}$} \\
\hline Alpha & 7.07 & 3.08 & $-\ddagger$ & 6.33 & 4.38 & 12.12 & 8.15 \\
\hline Badger & 7.33 & 3.27 & 6.45 & 5.17 & 4.38 & 11.06 & 8.31 \\
\hline Barton & 7.71 & 3.46 & 6.99 & 5.58 & 4.68 & 11.78 & 8.22 \\
\hline Beacon & 8.10 & 3.65 & 6.50 & - & 4.62 & - & 8.17 \\
\hline Carlton & 6.50 & 2.41 & 5.77 & - & 4.26 & - & 8.02 \\
\hline Lancaster & 6.46 & 3.70 & 6.58 & - & 4.01 & - & 7.72 \\
\hline Lincoln & - & - & 6.54 & 6.01 & 4.50 & 12.30 & 8.13 \\
\hline Lincoln-HDMD-C3 & 7.76 & 3.85 & 5.99 & 5.00 & 4.87 & 11.86 & 8.26 \\
\hline Lincoln-HDMDYD-C3 & $\mathbf{7 . 8 6}$ & 4.06 & 6.62 & 5.07 & 4.64 & 12.30 & 8.28 \\
\hline Lyon & $\mathbf{7 . 7 0}$ & 3.32 & 6.29 & 6.03 & 4.27 & 12.41 & 8.51 \\
\hline Magna & 6.56 & 2.80 & 6.04 & - & 4.91 & - & 7.65 \\
\hline Manchar & 7.85 & 2.53 & 5.89 & - & 3.11 & 10.53 & 8.59 \\
\hline NE-BI-1 & 7.86 & 3.76 & 6.24 & 5.14 & 5.29 & 12.77 & 8.14 \\
\hline NE-BI-2 & - & 3.28 & 5.98 & 4.20 & 4.20 & 12.09 & 8.41 \\
\hline PL-BDR1 & - & 3.58 & 6.69 & 5.24 & 4.98 & 10.93 & 7.94 \\
\hline Radisson & 6.85 & 3.11 & 6.43 & 5.53 & 5.24 & - & 8.87 \\
\hline Rebound & 6.63 & - & 6.09 & 5.28 & 4.42 & 11.91 & 8.17 \\
\hline Sac & 6.98 & 3.56 & 6.57 & 6.15 & 3.75 & 10.69 & 8.04 \\
\hline Saratoga & 7.22 & $\mathbf{3 . 3 7}$ & 6.19 & 5.54 & 4.49 & 11.94 & 8.14 \\
\hline Signal ${ }^{\circ}$ & 6.68 & 2.82 & 5.91 & - & 4.44 & - & 7.82 \\
\hline WB10-hD & - & - & 5.77 & - & 4.26 & - & 8.02 \\
\hline WB10-hDS & - & - & 6.20 & - & 4.32 & - & 8.10 \\
\hline WB10-1N & 6.97 & - & 5.92 & - & 4.36 & - & 8.37 \\
\hline WB19e & 8.40 & - & 6.39 & - & 5.15 & - & 8.77 \\
\hline WB20e & 8.54 & - & 6.42 & - & 4.47 & - & 8.03 \\
\hline PI 538862 & 5.73 & - & 5.42 & - & 3.69 & - & 7.46 \\
\hline PI 538859 & 6.02 & - & - & - & 3.91 & - & 7.84 \\
\hline PI 538863 & - & - & 5.18 & - & 3.85 & - & 7.01 \\
\hline York & 7.35 & 3.52 & 6.50 & 6.27 & 4.12 & 11.43 & 8.51 \\
\hline $\operatorname{LSD}(0.05)$ & 1.44 & 0.50 & 0.60 & 1.16 & 0.49 & 1.12 & 0.76 \\
\hline Mean & 7.22 & 3.32 & 6.21 & 5.50 & 4.40 & 11.74 & 8.13 \\
\hline
\end{tabular}

$\dagger$ IL $=$ Illinois, KS = Kansas, NE = Nebraska, NY = New York, ND =

North Dakota, WV $=$ West Virginia, and WI $=$ Wisconsin.

$\$$ Population not planted at that location or data missing. 
the model: $\mathrm{x}_{\mathrm{ijk}}=\mu+\mathrm{L}_{\mathrm{j}}+\mathrm{r}(\mathrm{L})_{\mathrm{k}(\mathrm{j})}+\mathrm{G}(\mathrm{L})_{\mathrm{i}(\mathrm{j})}+\varepsilon_{\mathrm{ijk}}$, where $\mu=$ the grand mean, $\mathrm{L}_{j}=$ the fixed effect of the jth location, $\mathrm{r}(\mathrm{L})_{\mathrm{k}(\mathrm{j})}=$ the random effect of the kth block within the jth location, $\mathrm{G}(\mathrm{L})_{\mathrm{i}(\mathrm{j})}=$ the fixed effect of the ith population within the jth location (i.e., the sum of the ith population effect, $G_{i}$, and the interaction effect of the ith population with the jth location, $\mathrm{GL}_{\mathrm{ij}}$, in a traditional factorial analysis), and $\varepsilon_{\mathrm{ijk}}=$ the random error effect for the ijkth plot. Sample estimates of $\mu$ and all $\mathrm{L}_{\mathrm{j}}$ values were zero, but these terms were retained in the model, because their deletion would artificially increase error degrees of freedom. The least squares means from this analysis $\left[\mathrm{g}_{\mathrm{i}(\mathrm{j})}\right]$ were equivalent to the quantities $\mathrm{M}_{\mathrm{ij} .}-\mathrm{M}_{\mathrm{j}}$, where $\mathrm{M}_{\mathrm{ij} .}=$ the mean of the ith population at the jth location and $\mathrm{M}_{\mathrm{j} .}=$ the mean of the jth location for the raw data $\left(\mathrm{X}_{\mathrm{ijk}}\right)$. Values of $\mathrm{g}_{\mathrm{i}(\mathrm{j})}$ were interpreted as follows: positive values indicated that a population was preferentially adapted to that location, negative values indicated lack of adaptation to that location, and values near zero indicated a population was near the mean for that location. The $\mathrm{g}_{\mathrm{i}(\mathrm{j})}$ values are a sum of the population effect and the population $\times$ location interaction effect from a traditional cross-classified factorial model and will be henceforth termed G+GL deviations.

The population $\times$ location interaction was estimated indirectly by computing specific location effects for each population, by means of the G+GL deviations. Each population had from two to six degrees of freedom for variation among the $\mathrm{G}+\mathrm{GL}$ deviations, depending on the number of locations at which it was tested (Table 1). Two of the six degrees of freedom for locations were used to test the following orthogonal effects for each population (Fig. 1): north (ND, WI, NY) vs. south (NE, KS, IL, WV); and west (KS, NE, ND) vs. east (WI, IL, NY, WV). Variation among populations in magnitude or significance for any of these location effects was used as an indicator of that population's contribution to population $X$ location interaction. All contrast effects, $P$-values, and leastsquares group means for the G+GL deviations were estimated as part of the mixed models analysis of the $\mathrm{x}_{\mathrm{ijk}}$ values (Littell et al., 1996). The effect of latitude was largely due to differential photoperiod, temperature, and snowfall or snow cover. The effect of longitude was largely due to differential precipitation, humidity, temperature, and soil type. No effort was made to separate these confounding factors of latitude or longitude.

Four new pseudovariables were computed to characterize the $\mathrm{G}+\mathrm{GL}$ deviations. These variables were the mean G+GL deviations for four geographic regions: north (ND, WI, NY), south (NE, KS, IL, WV), west (KS, NE, ND), and east (WI, IL, NY, WV). These four pseudovariables were first organized into four principal components, then the principal components were used to classify populations for their population $\times$ location interaction by Ward's method of cluster analysis (Milligan, 1980). The full cluster dendrogram was truncated at the point for which the sums of squares for the four principal components was partitioned as follows: $90 \%$ among clusters and $10 \%$ within clusters. Means of the four geographic pseudovariables were computed for each resulting cluster and contrasts were used to test differences between pairs of means for north vs. south and west vs. east. These latter contrasts and their $P$-values were computed in a spreadsheet, with error variances from the mixed models analyses of forage yield $\mathrm{G}+$ GL deviations.

\section{RESULTS AND DISCUSSION}

Eight populations showed a significant $(P<0.05)$ differential adaptation to northern vs. southern locations (Table 2). Four of these were meadow or intermediate climatypes (Carlton, Magna, PI 538859, and PI
Table 2. Mean G+GL deviations for forage yield of 29 smooth bromegrass populations evaluated at up to seven locations. Means are over three or four replicates, 2 or $3 \mathrm{yr}$, and all locations within each location grouping (North, South, West, or East). $\dagger$

\begin{tabular}{|c|c|c|c|c|c|c|}
\hline \multirow[t]{3}{*}{ Popula } & North & South & $P$-value $\S$ & West & East + & $P$-va \\
\hline & \multicolumn{6}{|c|}{$-\mathrm{Mg} \mathrm{ha}^{-1}$} \\
\hline & 0.31 & 0.05 & 0.2123 & -0.12 & 0.33 & 0.0397 \\
\hline Badger & -0.02 & -0.06 & 0.8659 & 0.07 & -0.13 & 0.3697 \\
\hline Barton & 0.18 & 0.40 & 0.3073 & 0.41 & 0.23 & 0.4022 \\
\hline Beacon & 0.16 & 0.50 & 0.1120 & 0.29 & 0.48 & 0.3853 \\
\hline CarltonII & -0.09 & -0.69 & 0.0053 & -0.49 & -0.39 & 0.6714 \\
\hline Lancaster & -0.37 & 0.00 & 0.0893 & 0.13 & -0.57 & 0.0011 \\
\hline Lincoln & 0.23 & 0.52 & 0.1830 & 0.23 & 0.43 & 0.3448 \\
\hline Lincoln-HDMD-C3 & 0.07 & 0.28 & 0.3180 & 0.27 & 0.13 & 0.5122 \\
\hline Lincoln-HDMDYD-C3 & 0.02 & 0.62 & 0.0048 & 0.48 & 0.28 & 0.3640 \\
\hline Lyon & 0.30 & 0.34 & 0.8316 & -0.01 & 0.57 & 0.0072 \\
\hline Magna & 0.05 & -0.45 & 0.0205 & -0.05 & -0.55 & 0.0192 \\
\hline Manc & -0.38 & -0.39 & 0.9784 & -0.79 & 0.02 & 0.0002 \\
\hline NE-BI-1 & 0.21 & 0.57 & 0.0941 & 0.46 & 0.38 & 0.7047 \\
\hline NE-BI-2 & -0.37 & 0.07 & 0.0372 & -0.15 & -0.15 & 0.9844 \\
\hline PL-BDR1 & 0.07 & 0.03 & 0.8241 & 0.45 & -0.35 & 0.0002 \\
\hline Radisson & 0.57 & -0.12 & 0.0013 & 0.29 & 0.16 & 0.5276 \\
\hline Rebound & -0.02 & -0.13 & 0.6041 & -0.04 & -0.10 & 0.7729 \\
\hline So & 0.01 & -0.14 & 0.5066 & -0.01 & -0.13 & 0.5793 \\
\hline Saratoga & 0.08 & 0.09 & 0.9540 & 0.05 & 0.12 & 0.7610 \\
\hline Signalרึ & -0.10 & -0.45 & 0.1063 & -0.25 & -0.41 & 0.4480 \\
\hline WB10-hD & -0.09 & -0.44 & 0.1081 & -0.28 & -0.07 & 0.3252 \\
\hline WB10-hDS & -0.03 & -0.01 & 0.9255 & -0.03 & 0.01 & 0.8619 \\
\hline WB10-1N & 0.13 & -0.27 & 0.0595 & -0.15 & 0.01 & 0.4540 \\
\hline WB19e & 0.73 & 0.68 & 0.8437 & 0.48 & 0.93 & 0.0348 \\
\hline WB20 & 0.02 & 0.77 & 0.0005 & 0.16 & 0.63 & 0.0268 \\
\hline PI 538862 & -0.66 & -1.14 & 0.0239 & -0.74 & -1.06 & 0.1340 \\
\hline PI 538859 II & $-\mathbf{0 . 3 6}$ & -1.21 & 0.0001 & -0.46 & -0.73 & 0.2057 \\
\hline PI 5 & -0.80 & -1.03 & 0.2956 & -0.78 & $-\mathbf{1 . 0 8}$ & 0.1498 \\
\hline York & 0.32 & 0.11 & 0.3251 & 0.08 & 0.30 & 0.3108 \\
\hline
\end{tabular}

† Positive values indicate a population mean that was higher than the location-group mean. Negative values indicate a population mean that was lower than the location-group mean.

+ North $=$ ND, WI, NY; South $=$ KS, NE, IL, WV; West $=$ ND, KS, NE; East $=$ WI, IL, NY, WV.

$\S \boldsymbol{P}$-value for comparing mean $\mathbf{G}+\mathrm{GL}$ deviation for North vs. South or West vs. East.

II Meadow or intermediate climatype.

538862) that are generally more adapted to northern latitudes in North America (Thomas et al., 1958), performing as expected in this study. Two of the other three meadow or intermediate climatypes showed a similar trend, but with $P>0.05$ (Signal and PI 538863). Radisson, developed in Canada, also demonstrated preferential adaptation to northern locations. Three populations with strong Nebraska pedigrees were preferentially adapted to the southern locations. Lincoln-HDMDYD-C3 was selected directly from Lincoln, NE-BI-2 was selected from plant introductions that were screened at Mead, $\mathrm{NE}$, and half of the pedigree of WB20e was derived from Lincoln and selections out of Lincoln. Lincoln itself and another Lincoln-derived population (LincolnHDMD-C3) showed similar trends, but with $P>0.05$.

Eight populations showed differential adaptation to western vs. eastern locations with $P<0.05$ (Table 2). Three of these were preferentially adapted to western locations: Lancaster, selected in Nebraska; Magna, an intermediate climatype selected in Saskatchewan; and PL-BDR1, a population selected in Pennsylvania for resistance to brown leafspot [caused by Pyrenophora bromi (Died) Drechs.]. PL-BDR1 has undergone four cycles of selection for resistance to brown leafspot, strictly in artificial indoor environments (Berg et al., 1986). It is unclear why it would be preferentially 


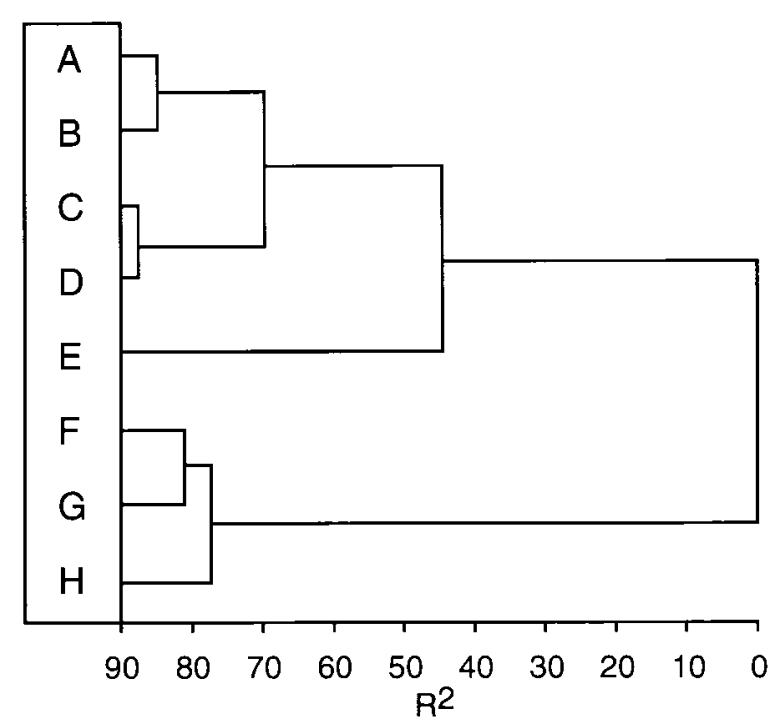

Fig. 2. Cluster dendrogram of 29 smooth bromegrass populations clustered on G+GL deviation pseudovariables to explain $90 \%$ of the total phenotypic variation within the four pseudovariables. Clusters contained the following populations: (A) Badger, Rebound, Sac, Saratoga, Lincoln-HDMD-C3, PL-BDR1, WB10-hDS, and WB10-IN; (B) Lancaster and NE-BI-2; (C) Carlton, Magna, Signal, and WB10-hD; (D) Manchar; (E) PIs 538859, 538862, and 538863; (F) Barton, Beacon, Lincoln, Lincoln-HDMDYD-C3, NEBI-1, and WB20e; (G) WB19e; and (H) Alpha, Lyon, Radisson, and York.

adapted to western environments where the brown leafspot organism is not prevalent. Three Wisconsin populations (Alpha, WB19e, and WB20e) were preferentially adapted to eastern locations, most likely reflecting their pedigree and selection history which are associated with the more humid and high-rainfall regions. The preferential adaptation of Lyon and Manchar to eastern locations was puzzling, as both were identified and selected under relative dryland conditions (the southern Great Plains and eastern Washington, respectively). This observation suggests that accessions and land races selected at a particular site or environment may not be best suited to that site or environment. There is no substitute to a broad regional yield test to determine adaptation range of smooth bromegrass cultivars.

Cluster analysis based on the four pseudovariables in Table 2 resulted in eight clusters that described $90 \%$ of the variation within Table 2 (Fig. 2). The eight clusters fell into three distinct groups on the basis of mean G + GL deviations (Table 3): Cluster A which contained populations of average forage yield across the entire region, Clusters B through E, which consisted of populations that were largely unadapted across the entire region, and Clusters $\mathrm{F}$ through $\mathrm{H}$, which consisted of populations that were specifically adapted to the entire region or a large part thereof. Cluster $\mathrm{E}$ was the most unique (Fig. 2) because it contained three plant introductions which were completely unadapted to the entire geographic region of this test (Table 3). These three PIs are meadow climatypes that were collected from the Altai Mtns. in southern Siberia. They appear to offer little to a smooth bromegrass breeding program for the central and eastern USA.
Table 3. Mean forage yield G+GL deviations for seven clusters of 29 smooth bromegrass populations and four pseudovariables (North, South, West, and East) used to generate the clusters. Means are over three or four replicates, 2 or 3 yr, all locations within each location group, and the stated number of populations $(n)$.

\begin{tabular}{|c|c|c|c|c|c|}
\hline \multirow[b]{2}{*}{ Cluster } & \multirow[b]{2}{*}{$n$} & \multicolumn{4}{|c|}{ Geographic location group $\dagger$} \\
\hline & & North & South & West & East \\
\hline & & & $-\mathbf{M}$ & -1 & \\
\hline $\mathbf{A}$ & 8 & $0.04 \div \S$ & -0.03 & 0.08 & -0.05 \\
\hline B & 2 & $-0.37 \mathrm{~B}$ & $0.04 \mathrm{~A}$ & $-0.01 \mathrm{~A}$ & $-0.36 \mathrm{~B}$ \\
\hline $\mathbf{C}$ & 4 & $-0.06 \mathrm{~A}$ & $-0.51 \mathrm{~B}$ & -0.26 & -0.36 \\
\hline D & 1 & -0.38 & -0.39 & $-0.79 B$ & $0.02 \mathrm{~A}$ \\
\hline $\mathbf{E}$ & 3 & $-0.61 \mathrm{~A}$ & $-1.13 B$ & $-0.66 \mathrm{~A}$ & $-0.96 \mathrm{~B}$ \\
\hline $\mathbf{F}$ & 6 & 0.14B & $0.56 \mathrm{~A}$ & 0.34 & 0.40 \\
\hline $\mathbf{G}$ & 1 & 0.73 & 0.68 & $0.48 B$ & $0.93 \mathrm{~A}$ \\
\hline $\mathbf{H}$ & 4 & $0.38 \mathrm{~A}$ & $0.09 \mathrm{~B}$ & $0.06 \mathrm{~B}$ & $0.34 \mathrm{~A}$ \\
\hline
\end{tabular}

$\dagger$ North $=$ ND, WI, NY; South $=$ KS, NE, IL, WV; West = ND, KS, NE; East $=$ WI, IL, NY, WV.

$\$$ North vs. South or West vs. East means are different from each other at $P<0.01$ if followed by different letters. Means without letters are not different between pairs of columns (North vs. South or West vs. East). "A" signifies the numerically higher member of a pair (higher mean forage yield).

$\S$ Italicized values are not significantly different from zero at $\boldsymbol{P}<0.05$.

The first principal component, which accounted for $83 \%$ of the variation among the four geographic pseudovariables, separated populations largely on the basis of the three cluster groupings described above (Fig. 3). Almost complete separation of these three groupings were obtained on the basis of the first principal component. The first two principal components, which together accounted for $92 \%$ of the variation, were sufficient to illustrate multidimensional separation of all eight clusters (Fig. 3).

Clusters C and D were most closely associated with Cluster E, the three Siberian PIs (Fig. 2 and 3). Clusters $\mathrm{C}$ and $\mathrm{D}$ had low mean G+GL deviations for three of the four geographic pseudovariables, while Cluster E had low mean values for all four pseudovariables (Table 3). Populations in Cluster $\mathrm{C}$ were better adapted to northern sites, while the population in Cluster D, Manchar, was better adapted to eastern sites. Four of the five populations in Clusters $\mathrm{C}$ and $\mathrm{D}$ were meadow or intermediate climatype cultivars (Carlton, Magna, Manchar, and Signal). The fifth population, WB10-hD is a steppe climatype developed at Wisconsin and probably clustered with the meadow and intermediate climatypes because of its uniformly below-average forage

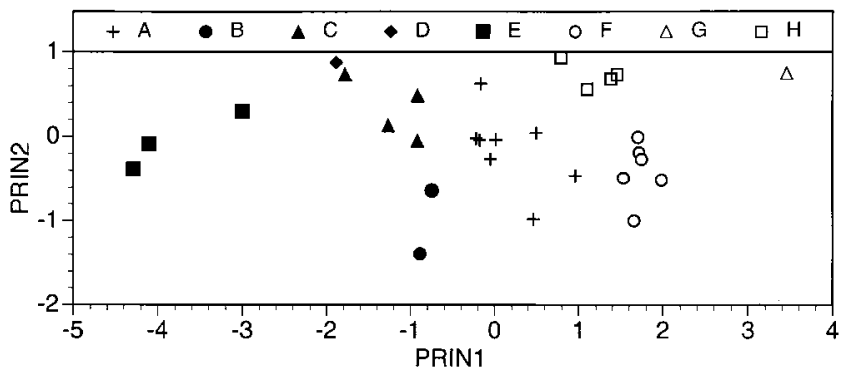

Fig. 3. Multidimensional scale plot of the first two principal components of the four geographic pseudovariables. Letters A-H are cluster identifications (Fig. 2 and Table 3). Crosses indicate populations of moderate adaptation, closed symbols indicate populations largely unadapted across the entire region, and open symbols indicate populations highly adapted to the entire region or a part thereof. 
yield potential (Table 1). Populations in Cluster B, Lancaster and NE-BI-2, were relatively unadapted to northern or eastern sites, but only of moderate adaptation to southern or western sites (Table 3). Because both Lancaster and NE-BI-2 originated in the southern Great Plains, it is logical that they be best adapted to that part of the region shown in Fig. 1. However, their lack of high positive $G+G L$ deviations indicates that these two populations showed only moderate adaptation to sites within their zone of origin.

Clusters F, G, and $\mathrm{H}$ are the most interesting, because they consist generally of populations with high mean forage yield (large and positive G+GL deviations) with a relatively broad adaptation range (positive G+GL deviation across the geographic range). Cluster $\mathrm{F}$ consists of six populations that were selected in Iowa (Barton and Beacon), Nebraska (Lincoln, Lincoln-HDMDYD-C3, and NE-BI-1), or Wisconsin (WB20e). Barton is $25 \%$ Lincoln, Beacon is $38 \%$ Lincoln, and WB20e is $50 \%$ Lincoln (Alderson and Sharp, 1994). NE-BI-1 is derived largely from plant introductions that were subjected to selection in eastern Nebraska. While Cluster F had positive and significant mean G+GL deviations for all four geographic regions, its populations were more adapted to southern vs. northern locations $(P<0.01$, Table 3), probably reflecting the strong Lincoln pedigree and strong influence of the Nebraska selection location in this cluster.

Cluster $\mathrm{H}$ is very interesting because the four cultivars (Alpha, Lyon, Radisson, and York) were bred or selected at four diverse sites (Wisconsin, Nebraska, Saskatchewan, and New York, respectively) and share little to no germplasm in their pedigrees (Alderson and Sharp, 1994). These cultivars were preferentially adapted to northern vs. southern sites and eastern vs. western sites, apparently reflecting the influence of breeding programs in Wisconsin, Saskatchewan, and New York. Alleles for superior forage yield across multiple sites appear to be distributed widely among diverse smooth bromegrass germplasm sources.

Finally, Cluster G, consisting solely of WB19e, was the only cluster that could be characterized as superior in adaptation in all four zones (Table 3). WB19e is a strain cross between Lincoln-derived selections (at Lincoln, NE) and Alpha- and Badger-derived selections (at Arlington, WI), all selected for high yield and IVDMD (Casler et al., 2000). Part of the superior performance of WB19e may derive from heterosis between the Nebraska and Wisconsin selections, suggesting the existence of complementary dominant alleles for forage yield between the two programs (Brummer, 1999). This could also explain the unusual stability for high forage yield of WB19e across the four geographic zones.

\section{CONCLUSIONS}

The adaptation of Lin and Binns' method of pooling the population main effect with the population $\times$ loca- tion interaction provided us with a mechanism for developing inferences about GL interactions in a highly unbalanced data set. Smooth bromegrass populations were rather easily clustered into groups that reflected differences in forage yield potential and differential adaptation to zones within the central and eastern USA. Much of the grouping and adaptation characteristics could be explained by similar pedigrees, selection history, and selection location. However, the phenotypic similarity of some superior, but divergent-pedigree populations suggested that alleles for high and stable forage yield in smooth bromegrass probably exist in numerous germplasm sources. If many of these alleles are complementary, and the performance of WB19e suggests this possibility, this indicates considerable potential for future improvements of forage yield of smooth bromegrass. Key to utilizing these diverse sources of alleles will be maximizing recombination among diverse germplasm sources or, if heterotic groups can be identified, strain crossing between complementary heterotic germplasm sources.

\section{REFERENCES}

Alderson, J., and W.C. Sharp. 1994. Grass varieties in the United States. Agric. Handb. No. 170 (Revised). U.S. Gov. Print. Office, Washington, DC.

Berg, C.C., R.T. Sherwood, and K.E. Zeiders. 1986. Recurrent phenotypic selection for resistance to brown leaf spot in smooth bromegrass. Crop Sci. 26:533-536.

Brummer, E.C. 1999. Capturing heterosis in forage crop cultivar development. Crop Sci. 39:943-954.

Casler, M.D., K.P. Vogel, J.A. Balasko, J.D. Berdahl, D.A. Miller, J.L. Hansen, and J.O. Fritz. 2000. Genetic progress from 50 years of smooth bromegrass breeding. Crop Sci. 40:13-22.

Fehr, W.R. (ed.) 1984. Genetic contributions to yield gains of five major crop plants. CSSA Spec. Publ. No. 7. ASA, CSSA, and SSSA, Madison, WI.

Fortman, H.R. 1953. Responses of varieties of bromegrass (Bromus inermis Leyss.) to nitrogen fertilizer and cutting treatments. Cornell Univ. (New York) Agric. Exp. Stn. Memoir 322.

Hanson, A.A. 1972. Grass varieties in the United States. Agric. Handb. No. 170. U.S. Gov. Print. Office, Washington, DC.

Knowles, R.P., and W.J. White. 1949. The performance of southern strains of brome grass in Western Canada. Sci. Agric. 29:437-450.

Lin, C.S., and M.R. Binns. 1988. A method for assessing regional trial data when the test cultivars are unbalanced with respect to locations. Can. J. Plant Sci. 68:1103-1110.

Littell, R.C., G.A. Milliken, W.W. Stroup, and R.D. Wolfinger. 1996. SAS systems for mixed models. SAS Inst., Cary, NC.

Milligan, G.W. 1980. An examination of the effect of six types of error perturbation on fifteen clustering algorithms. Psychometrica 45:325-342.

Thomas, H.L., E.W. Hanson, and J.A. Jackobs. 1958. Varietal trials of smooth bromegrass in the North Central region. Minnesota Agric. Exp. Stn. Misc. Rep. 32.

Veronesi, F. 1991. Achievements in fodder crop breeding in Mediterranean Europe. p. 25-30. In A.P.M. den Nijs and A. Elgersma (ed.) Fodder crops breeding: Achievements, novel strategies, and biotechnology. Pudoc, Wageningen, the Netherlands.

Vogel, K.P., K.J. Moore, and L.E. Moser. 1996. Bromegrasses. p. 535-567 In L.E. Moser et al. (ed.) Cool-season forage grasses. Agron. Monogr. 34. ASA-CSSA-SSSA, Madison, WI. 